\title{
Effects of Pulmonary Rehabilitation on Exercise Tolerance in Patients with COPD
}

\author{
Mohammad Nesar Uddin Ahmed ${ }^{1}$, Shelina Begum², Taskina Ali ${ }^{3}$
}

\begin{abstract}
Background: Pulmonary rehabilitation (PR) is known to be therapeutically useful for COPD patients. Objective: To evaluate the effects of combination of breathing exercises (pursed lip breathing and diaphragmatic breathing) and lower extremity endurance training (LEET) as part of PR program on six minute walk distance (6MWD), on oxygen saturation $\left(\mathrm{SpO}_{2} \%\right)$, on the level of dyspnea and fatigue in patients with moderate stable COPD. Methods: This prospective study was conducted in the Department of Physiology, BSMMU, Dhaka from July 2010 to June 2011 on 116 male stable moderate COPD patients aged 50 to 65 years. They were enrolled from the out patient department (OPD) of the Department of Medicine of BSMMU and NIDCH Dhaka. 56 patients without PR constituted control group and experimental group included 60 patients intervened with PR. The experimental patients were advised to perform the PR program for 30 minutes duration per session at home twice daily, for consecutive 60 days along with the standard drug treatment of COPD. The control patients were advised to continue their standard drug treatment alone for consecutive 60 days. For the assessment of exercise tolerance, $6 \mathrm{MWD}, \mathrm{SpO}_{2} \%$, the level of dyspnea and fatigue of all subjects were recorded on day 0 and day 60 for both the groups. $\mathrm{SpO}_{2} \%$ was recorded by portable Pulse Oximeter and the level of dyspnea as well as fatigue were recorded by Modified Borg Scale. Statistical analysis was done by independent sample ' $t$ ' test and paired sample ' $t$ ' test. Results: Significant improvement were observed in $6 \mathrm{MWD}, \mathrm{SpO}_{2} \%$, the level of dyspnea and fatigue in patients who performed PR program. In addition, significant improvement in these parameters were observed after completing PR program compared to the beginning of the intervention. Conclusion: The study concludes that regular exercise of all components of PR program significantly improve exercise tolerance in COPD patients.
\end{abstract}

Key words: Pulmonary rehabilitation, COPD, six minute walk distance, oxygen saturation, level of dyspnea, Borg score.

Bangladesh Soc Physiol. 2014, December; 9(2): 65-71

For Authors Affiliation, see end of text.

http://www.banglajol.info/index.php/JBSP

\section{Introduction}

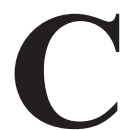

hronic Obstructive Pulmonary Disease (COPD) is one of the major causes of chronic morbidity and mortality throughout the world ${ }^{1}$. It is the fourth leading cause of death in adults of United States and also projected to be the third by $2020^{2}$. According

Received March 2014; Accepted June 2014 to Global Initiative for Chronic Obstructive Lung Disease, COPD is a preventable and treatable disease. However, once developed this disease along with its comorbidities can not be cured, though its progression and morbidity can be reduced $^{1}$.

The pulmonary component of COPD is characterized by airflow limitation caused by a 
mixture of small airways disease (obstructive bronchiolitis) and parenchymal destruction (emphysema). In addition, chronic inflammation causes structural changes and narrowing of the small airways with subsequent decrement in ventilation $^{1}$.

The six minute walk test (6MWT) was first used in the clinical setting to test exercise tolerance in individuals with chronic respiratory disease such as $\mathrm{COPD}^{3}$. Reduced exercise tolerance is a hallmark of patients with COPD. Patients with COPD often presents with limited physical activity and poor exercise capacity ${ }^{4}$. Functional exercise capacity can be assessed by measuring the distance walked during any period of time ${ }^{5}$. Walk test are typically administered as a common method to evaluate functional status for monitoring treatment effectiveness and establishing prognosis in COPD patients. The $6 \mathrm{MWT}$ is a practical simple test that requires a 30 meter hallway but no exercise equipment. The test measures, the distance that a person can quickly walk on a flat, hard surface in a period of 6 minutes 5 .

The 6MWT is easy to administer, better tolerated and more reflective of activities of daily living than the other walk tests ${ }^{6}$. The self-paced 6MWT assesses the submaximal level of functional capacity. During the $6 \mathrm{MWT}$, patients are instructed to walk as far as possible in the allowed six minutes. Patients are allowed to stop and rest during the test, but rest periods form part of the six minute period ${ }^{7}$. Most protocols do not allow for the use of a treadmill, due to underestimation of exercise ability ${ }^{5}$. Stevens and co-workers found that when using a treadmill, walking distance was shorter by a mean of $14 \%$, compared to corridor distances ${ }^{8}$. However, because most activities of daily living are performed at submaximal levels of exertion, the 6MWD may better reflect the functional exercise level for daily physical activities $^{5}$. The primary measurement of $6 \mathrm{MWT}$ is the total distance walked. Secondary measures can include fatigue and dyspnea, measured with a modified Borg scale ${ }^{9}$. Oxygen saturation $\left(\mathrm{SpO}_{2} \%\right)$ is an indicator of the percentage of Hemoglobin saturated with oxygen at the time of the measurement which is an index of the patient's oxygenation status. It varies with oxygen utilization by the tissues during exercise ${ }^{10}$. Arterial oxygen saturation can also be measured via pulse oximetry, as long as the oximeter is portable and not heavy ${ }^{9}$. Dyspnea is one of the most significant symptoms occurring during the progression of COPD ${ }^{11-12}$. Severity of dyspnea cannot be evaluated satisfactorily by spirometric or gas analysis but the effort dyspnea determined at the end of exercise is the best assessor of dyspnea profile. Among several scale, Modified Borg Scale (MBS) is commonly been used to evaluate the effort of dyspnea and the level of fatigue in clinical practice. In this procedure 0-10 rated scale was used to estimate different levels of dyspnea and fatigue. The scaling was done from the statement of the patients according to their subjective sensation ${ }^{11}$. Leupoldt et al. therefore examined verbal descriptors of dyspnea in patients with COPD at different intensity levels of dyspnea during rest, before and after $6 \mathrm{~min}$ walk test ${ }^{13}$.

PR is an evidence-based, multidisciplinary and comprehensive intervention for patients with chronic respiratory diseases who are symptomatic and often have decreased daily life activities ${ }^{14}$. According to GOLD standard, PR aims to reduce the symptoms, to improve quality of life, and to increase the physical and emotional participation of COPD patients in everyday activities ${ }^{1}$. The minimum length of an effective rehabilitation program has been suggested as 6 (six) weeks ${ }^{1}$.

Medicines might have a limited role in improving the physical capacity in COPD patients. Pursed lip breathing (PLB) and diaphragmatic breathing (DB) and LEET as component of PR have been found to improve exercise tolerance. Home based PR has been advocated to patients for its various $\operatorname{advantages}^{15}$. 
Though several investigation on effect of PR on COPD has been reported but no study observed the effects of combination of more than one component of PR program on exercise tolerance in stable COPD patients. Therefore, the present study has been designed to evaluate the effects of combination of PLB, DB and LEET on exercise tolerance in male patients with moderate stable COPD.

\section{Methods}

This prospective study with exercise intervention was carried out from July 2010 to June 2011 in the Department of Physiology, Bangabandhu Sheikh Mujib Medical University (BSMMU), Shahbag, Dhaka. The study protocol was approved by Ethical Review Committee (ERC) of BSMMU. A total number of 116 male stable (without any exacerbation for last 4 weeks ${ }^{16}$ ) moderate COPD $\left(\mathrm{FEV}_{1}<80 \%\right.$ but e" $50 \%$ of predicted $\left.{ }^{1}\right)$ patients aged 50 to 65 years were selected from the OPD of the Department of Medicine (Respiratory medicine unit) of BSMMU and the Department of Medicine of National Institute of Diseases of the Chest and Hospital (NIDCH), Mohakhali, Dhaka by systematic random sampling. 56 patients without PR served as control and 60 patients with PR served as experimental. They were assessed on day 0 and on day 60 . Subjects with the history of bronchial asthma, bronchiectasis, respiratory failure, pneumothorax, pleural effusion, pulmonary tuberculosis, pulmonary fibrosis, pneumonectomy or pulmonary lobectomy etc, any cardiovascular diseases ${ }^{17}$, diabetes mellitus (Fasting plasma glucose $>7 \mathrm{mmol} / \mathrm{dl}^{18}$ ), irritable bowel syndrome ${ }^{19}, \mathrm{SLE}^{20}$, systemic hypertension (SBP e" 140 and DBP e" $90 \mathrm{~mm}$ of $\mathrm{Hg}^{21}$ ), any malignancy or renal disease (Serum creatinine $>1.36 \mathrm{mg} / \mathrm{dl}^{22}$ ), were excluded from the study. PR program included PLB, DB and LEET in the form of walking ${ }^{15}$ for 30 minutes duration per session and were performed at home twice daily, for consecutive 60 days along with the standard drug treatment of COPD. In the technique of PLB, patients inhaled through the nose with mouth closed, and then exhaled through mouth with lips pursed tightly. The exhalation was twice as long as the inhalation. In the technique of $\mathrm{DB}$, the patients were asked to exhale slowly through pursed lips while drawing the abdomen inward, and inhale slowly through the nose so that the abdomen would expand outward. In the technique of LEET It was performed at home or on a flat track. Subjects was asked to walk as much as he can with a submaximal speed twice a day. During walking, he was used pursed lip breathing 15 .

After selection, all the patients were thoroughly informed about the aim, objectives and procedure of the study and were encouraged for their voluntary participation. Then an informed written consent was taken from each subject. A detail personal, medical, family, socioeconomic, occupational and drug history were recorded in a preformed data schedule and thorough physical examinations were done and documented. For the assessment of exercise tolerance, 6MWD of all subjects were performed at indoors, along a long, flat, straight, enclosed corridor with a hard surface that was seldom travelled ${ }^{3}$. The walking course was 30 meter in length which was marked every 3 meter. The turnaround points were marked with a cone. A starting line, which marked the beginning and end of each 60 meter lap, was marked on the floor using brightly colored tape ${ }^{3}$. The subject was asked to walk at his own maximal pace along the corridor from the end, covering as much ground as he can, during the allotted time, without running. He was also advised to take rest if he was too exhausted to continue the test. Standard phrases at regular intervals (every 60 seconds) was used, like: "you are doing well," "keep up the good work" " 3 . At the same time he was also 
informed about the passed time and how much was left before the test was completed. If any of the subject developed chest pain, intolerable dyspnea, leg cramps, staggering, diaphoresis or pale appearance the test was immediately stopped and the subject was dropped. Again when any subject completed the total study procedure (according to the exact study design), he was congratulated for good effort ${ }^{3}$. For the assessment of exercise tolerance $\mathrm{SpO}_{2} \%$ of all subjects were recorded by a portable Pulse Oximeter (H10 Finger Oximeter, described by EDAN INSTRUMENTS INC) at right index finger. Fatigue as well as level of dyspnea were recorded by Modified Borg Scale.

\section{The Modified Borg Scale Sc $^{23}$}

\begin{tabular}{ll}
\hline Scale & Severity \\
\hline 0 & No Breathlessness at all \\
0.5 & Very very slight (just noticeable) \\
1 & Very Slight \\
2 & Slight Breathlessness \\
3 & Moderate \\
4 & Somewhat severe \\
5 & Severe Breathlessness \\
6 & \\
7 & Very Severe Breathlessness \\
8 & \\
9 & Very very Severe (Almost Maximum) \\
10 & Maximum \\
\hline
\end{tabular}

All the variables were measured in both the groups, on the very first day of the study and also at $60^{\text {th }}$ days after the exercise. Data were expressed as mean \pm SD and were statistically analyzed by SPSS (Version 16.0) using independent sample ' $t$ ' test and paired student's ' $t$ ' test, as applicable. In the interpretation of results, $p<0.05$ was accepted, as level of significance.

\section{Results}

All of the participants were similar in respect of age, height, duration of COPD, duration of smoking, socioeconomic status and occupation. (Table I)

After 60 days follow up, mean 6MWD and $\mathrm{SpO}_{2} \%$ were increased in both the groups, but the increment were significant only in the COPD with PR. (Table II)

On the other hand, mean Borg score for dyspnea and fatigue were significantly decreased (improved) in patients with PR but it was increased but no significant in patients without PR after 60 days. (Table II)

More over all these parameters showed increased exercise tolerance in COPD patients with PR compared to without PR after 60 days.

Table I: Socio demographic characteristics of different groups $(\mathrm{n}=116)$

\begin{tabular}{lcc}
\hline Parameters & $\begin{array}{c}\text { COPD patient } \\
\text { without PR } \\
(\mathrm{n}=56)\end{array}$ & $\begin{array}{c}\text { COPD patient } \\
\text { with PR } \\
(\mathrm{n}=60)\end{array}$ \\
\hline Age (years) & $58.91 \pm 4.05$ & $58.58 \pm 4.12$ \\
& $(50-65)$ & $(50-65)$ \\
Height (meters) & $1.655 \pm 0.03$ & $1.651 \pm 0.03$ \\
& $(1.58-1.72)$ & $(1.57-1.71)$ \\
Duration of & $3.04 \pm 1.12$ & $3.41 \pm 1.22$ \\
COPD (years) & $(0.5-5)$ & $(1-5)$ \\
Duration of smoking & $15.41 \pm 4.16$ & $16.80 \pm 4.38$ \\
(pack years) & $(11-25)$ & $(11-25)$ \\
Socioeconomic statue & $1.63 \pm 0.78$ & $1.88 \pm 0.83$ \\
(score) & $(1-4)$ & $(1-4)$ \\
Occupation (score) & $2.04 \pm 1.06$ & $2.37 \pm 1.06$ \\
& $(1-4)$ & $(1-4)$ \\
\hline
\end{tabular}

Data were expressed as mean \pm SD. Figures in parentheses indicate ranges. Statistical analysis was done with independent sample ' $t$ ' test and Chi-square test $\left(\chi^{2}\right)$. 
Table II: Exercise tolerance in different groups in different periods ( $\mathrm{n}=116)$

\begin{tabular}{lccccc}
\hline Parameter & \multicolumn{2}{c}{ COPD without PR $(\mathrm{n}=56)$} & & \multicolumn{2}{c}{ COPD with PR $(\mathrm{n}=60)$} \\
\cline { 2 - 3 } \cline { 6 - 6 } & Day 0 & Day 60 & & Day 0 & Day 60 \\
\hline 6MWD (meter) & $293.18 \pm 51.95$ & $299.54 \pm 54.43^{\#}$ & & $289.60 \pm 49.45$ & $340.17 \pm 56.60^{\# \# \# * * *}$ \\
$\mathrm{SpO}_{2}$ \% at rest & $95.16 \pm 1.28$ & $95.30 \pm 1.28$ & & $95.07 \pm 1.60$ & $95.48 \pm 1.53^{\# \#+\#^{* * *}}$ \\
Borg score at rest (Dyspnea) & $3.73 \pm 0.92$ & $3.84 \pm 1.19$ & & $3.88 \pm 0.98$ & $3.03 \pm 1.12^{\# * * *}$ \\
Borg score at rest (Fatigue) & $3.50 \pm 0.93$ & $3.75 \pm 0.9$ & & $3.57 \pm 1.08$ & $3.00 \pm 1.19^{\# \# \# * * *}$ \\
\hline
\end{tabular}

Data were expressed as mean \pm SD. Statistical analysis was done by unpaired and paired student $\mathrm{t}$ test. \#Day 0 and Day 60 ( \# $\mathrm{p}<0.5$; \#\#\# $\mathrm{p}<0.001)$; * Day 60 vs Day 60(*** $\mathrm{p}<0.001)$

\section{Discussion:}

The present study shows significant improvement of $6 \mathrm{MWD}$ and $\mathrm{SpO}_{2} \%$ at resting condition in pulmonary rehabilitated COPD patients after 60 days of follow up and it was further improved compared to the patient without PR. Similar observation were reported by several investigators ${ }^{15,24-28}$. In addition, significant improvement in mean Borg score was observed in PR intervened patients but it was not improved in patients without PR after 60 days. Similar observation were also reported by several investigators ${ }^{26,29}$.

From this study, the exact mechanisms of the derangement of $6 \mathrm{MWD}$ and $\mathrm{SpO}_{2} \%$ at resting condition in COPD and the beneficiary effects of PR program on exercise tolerance in stable COPD patients could not be elucidated. But literature review suggested that, decreased skeletal muscle mass in the periphery may cause loss of endurance and strength of peripheral muscles to produce decrement in 6MWD in COPD patients $^{24}$. Moreover, restricted working capability for dyspnea may produce disuse atrophy in the peripheral limb muscles which may act as a factor for decrement in peripheral muscle load and muscle wasting in stable COPD patients may cause decrement in overall skeletal muscle mass which may produce exercise intolerance ${ }^{25}$. Again, hyperinflation and overstretching of the alveoli and airway may decrease diffusing membrane surface area for gaseous exchange and diffusing capacity of respiratory membrane in COPD patients may cause decreased oxygenation of blood and ultimately decreased systemic arterial $\mathrm{SpO}_{2} \%$ and increased $\mathrm{PCO}_{2}{ }^{26}$. Decreased elastic recoil of the alveoli and the small airways may cause decreased alveolar ventilation, which may be an important additional responsible component for decreased $\mathrm{SpO}_{2} \%$ in stable COPD patients ${ }^{26}$. Moreover, this hypercapnea may stimulate the ventilatory drive and ultimately increase perception of dyspnea in this group of patients ${ }^{27}$.

It has been suggested that regular PLB may decrease the amount of the trapped air in the lungs followed by decreased work of breathing 28 causing relief of dyspnea ${ }^{28,29}$ and increase in $\mathrm{SpO}_{2} \%{ }^{30}$ and ultimately increase in $6 \mathrm{MWD}^{31}$. Therefore, improvement in $\mathrm{SpO}_{2} \%$ and $6 \mathrm{MWD}$ might be expected after this sort of PR program in stable COPD patients. In addition, it has been reported that regular LEET may increase exercise tolerance by increasing $6 \mathrm{MWD}^{15,32-36}$. Here LEET may cause increased capillary network of the less used peripheral as well as respiratory skeletal muscles followed by increased tissue oxygenation and protein synthesis of them ${ }^{15}$. As a consequence, there may be a great increment in muscle mass which may be the cause of significant improvement in BMI and 6MWD of the experimental patients in our study. 


\section{Conclusion}

From this study, it may be concluded that exercise tolerance was greatly improved after implementation of regular PR program in male patients with moderate stable COPD.

\section{Acknowledgement}

Authors of this study are thankful to the authority of the Department of Medicine (Respiratory medicine unit), BSMMU and the Department of Medicine, NIDCH, for their nice cooperation during sample collection and also thankful to the study subjects for their active and enthusiastic participation.

\section{Author affiliations}

1. *Mohammad Nesar Uddin Ahmed. Associate Professor, Department of Physiology, Ad-din Sakina Medical College, Jessore.Bangladesh Email: nesarj9@gmail.com

2. Shelina Begum. Professor and Chairman, Department of Physiology, Bangabandhu Sheikh Mujib Medical University (BSMMU), Shahbag, Dhaka. Email: shelina1985@gmail.com

3. Taskina Ali. Associate professor, Department of Physiology, Bangabandhu Sheikh Mujib Medical University (BSMMU), Shahbag, Dhaka. Email: taskinadr@gmail.com

*For correspondence

\section{References}

1. Global Initiative for Chronic Obstructive Lung Disease. Global strategy for the diagnosis, management and prevention of COPD. NIH Publication; 2008.

2. Finkelstein J, Cha E \& Scharf SM. Chronic Obstructive Pulmonary disease as an independent risk factor for cardiovascular morbidity. Int J Chron Obstruct Pulmon Dis. 2009; 4: 337-349.

3. Rabinovich RA, Vilaro J, Roca J. Evaluation exercise tolerance in COPD patients: 6-minute walking test. Arch Bronconeumol. 2004; 40(2): 80-85.

4. Balke B. A simple field test for the assessment of physical fitness. CARI Report. 1963; 63: 18.

5. American Thoracic Society (ATS). ATS Statement: Guidelines for the six minute walk test. Am J Respir Crit Care Med. 2002; 166: 111-117.

6. Solway S, Brooks D, Lacasse Y, Thomas S. A qualitative systematic overview of the measurement properties of functional walk tests used in the cardiorespiratory domain. Chest. 2001; 119: 256270 .

7. Redelmeier DA, Bayoumi AM, Goldstein RS, Guyatt $\mathrm{GH}$. Interpreting small differences in functional status: The six minute walk test in chronic lung disease patients. Am J Respir Crit Care Med. 1997; 155: 1278-1282.

8. Stevens D, Elpern E, Sharma K, Szidon P, Ankin M, Kesten S. Comparison of hallway and treadmill six-minute walk tests. Am J Respir Crit Care Med. 1999; 160: 1540-1543.

9. Enright PL. The six-minute walk test. Respiratory Care. 2003 ; 48(8): 783-785.

10. Schutz SL. Oxygen saturation monitoring by pulse oximetry. In: AACN procedure manual for critical care, $4^{\text {th }}$ ed. Philadelphia: W.B.Saunders, 2001. 7782 .

11. Kendrick KR, Baxi SC, Smith RM. Usefulness of the modified 0-10 Borg scale in assessing the degree in patients with COPD and asthma. J Emerg Nurs. 2000; 26: 216-222.

12. Ali T, Begum N, Hassan MR, Bennoor KS. Effect of dietary modifications on some aspects of anthropometry and pulmonary functions in patients with chronic obstructive pulmonary disease. Bangladesh Journal of Physiology and Pharmacology (ISSN 1561-1566). 2003 Jan/Jul; 19(1/2): 24-27.

13. Leupoldt AV, Balewski S, Petersen S, Taube K, Schubert-Heukeshoven S, Magnussen H, Dahme B. Verbal descriptors of dyspnea in patients with COPD at different intensity levels of dyspnea. Chest. 2007; 132: 141-147.

14. Nici L, Donner C, Wouters E, Zuwallack R, Ambrosino N, Bourbeau J, Carone M, Celli B, Engelen M, Fahy B, Garvey C, Goldstein R, Gosselink R, Lareau S, Maclntyre N, Maltais F, Morgan M, O'Donnell D, Prefault C, Reardon J, Rochester C, Schols A, Singh S, Troosters T. American Thoracic Society/ European Respiratory Society statement on pulmonary rehabilitation. Am J Respir Crit Care Med. 2006; 173: 1390-1413.

15. Singh V, Khandelwal DC, Khandelwal R, Abusaria S. Pulmonary rehabilitation in patients with chronic obstructive pulmonary disease. Indian Chest Dis Allied Sci. 2002; 45: 13-17.

16. McAllister DA, Maclay JD, Mills NL, Mair G, Miller J, Anderson D, Newby DE, Murchison JT, MacNee 
William. Arterial Stiffness Is Independently Associated With Emphysema Severity in Patients with Chronic Obstructive Pulmonary Disease. Am J Respir Crit Care Med. 2007; 176:1208 -1214.

17. Reid PT, Innes JA. Respiratory disease. In: Colledge NR, Walker BR, Ralston SH, editors. Davidson's principles and practice of medicine. $21^{\text {st }}$ ed. China: Elsevier Limited; 2010. p642-730.

18. WHO Definition, Diagnosis and Classification of Diabetes Mellitus and its complication. Report of a WHO Consultation. Geneva: WHO; 1999.

19. Clark C, DeLegge M. Irritable bowel syndrome: a practical approach. Nutr Clin Pract. 2008; 23: 263267.

20. Hahn BH. Systemic Lupus Erythematosus. In: Kasper D, Braunwald E, Fauc AS, Hausen SL, Longo DL. editors. Harrison's Principles of Internal Medicine. NY: MC Graw-Hill; 2005. p1960-1967.

21. Newby DE, Grubb NR, Bradbury A. Cardiovascular disease. In: Colledge NR, Walker BR, Ralston SH, editors. Davidson's principles and practice of medicine. $21^{\text {st }}$ ed. China: Elsevier Limited; 2010. $606 \mathrm{p}$.

22. Walker SW. Laboratory reference rate. In: College NR, Walker BR, Ralston SH, editors. Davidson's Principles and Practice of Medicine. Churchil Livingstone: Elsevier; 2010. p230-251.

23. Burdon JGW, Juniper EF, Killian KJ, Hargrave FE, Campbell EJM. The perception of breathlessness in asthma. Am Rev Respir Dis. 1982; 126: 825828 .

24. Gosselink R, Troosters $\mathrm{T}$ and Decramer $\mathrm{M}$. Peripheral muscle weakness contributes to exercise limitation in COPD. Am J Respir Crit Care Med. 1996; 153: 976-980.

25. Jagoe RT, Engelen MPKJ. Muscle wasting and changes in muscle protein metabolism in chronic obstructive pulmonary disease. Eur Respir J. 2003; 22: $52-63$.
26. Guyton AC, Hall JE. Textbook of Medical Physiology. $12^{\text {th }}$ ed. Singapore: Saunders Elsevier; 2011. p465-523.

27. Mahler DA. Mechanisms and measurement of dyspnea in chronic obstructive pulmonary disease. Proc Am Thorac Soc. 2006; 3: 234-238.

28. Ingram RM, Schilder DP. Effect of pursed lips expiration on the pulmonary pressure-flow relationship in obstructive lung disease. Am Rev Respir Dis. 1967; 96: 381-388.

29. Mueller RE, Petty TL, Filley GF. Ventilation and arterial blood gas changes induced by pursed lips breathing. J Appl Physiol. 1970; 28: 784-789.

30. Motley HL. The effects of slow deep breathing on the blood gas exchange in emphysema. Am Rev Respir Dis. 1963; 88: 484-492.

31. 24. Watchie J. Cardiopulmonary physical therapy treatment: A clinical manual. $1^{\text {st }}$ ed. Philadelphia, Pa: WB Saunders; 1995. p208-212.

32. 25Niderman MS, Clemente PH, Fein AM, Feinsilver SH, Robinson DA, Ilowite JS, Bernstein MG. Benefits of a multidisciplinary pulmonary rehabilitation program. Improvements are independent of lung function. Chest. 1991; 99: 798-804.

33. 26 Berry MJ, Rejeski WJ, Adair NE, Zaccaro D. Exercise rehabilitation and chronic obstructive pulmonary disease stage. Am J Respir Crit Care Med. 1999; 160: 1248-1253.

34. 27 Hernandez MT, Rubio TM, Ruiz FO, Riera HS, Gil RS, Gomez JC. Results of a home based training program for patients with COPD. Chest. 2000; 118: 106-114

35. 28Santiworakul A, Jarungjitaree S, Jalayondeja W, Chantarothorn S, Supaibulpipat S. Effect of Lower Extremity Exercise on Muscle Strength and Physical Capacity in COPD Patients. J Med Asso Thai. 2009; 92(4): 556-563.

36. 29 Wijkstra PJ, Altena RV, Kraan J, Otten V, Postma DS, Koeter GH. Quality of life in patients with chronic obstructive pulmonary disease improves after rehabilitation at home. Eur Respir J. 1994; 7: 269-273. 